\title{
Comparative Study of Computer Assisted Instruction and Traditional Methods of Teaching Keyboarding among Polytechnic Students
}

\author{
Olayinka Taiye Oyinloye ${ }^{1}$ Joshua Sule Mamman $\mathrm{PhD}^{3 *}$ \\ Lanre Akewusola $^{1}$ James Kehinde Ayeni ${ }^{2}$ \\ 1.Department of Office Technology and Management, \\ Institute of Information and Communication Technology, Kwara State Polytechnic, Ilorin. \\ Kwara State, Nigeria \\ 2.Department of Computer Science, \\ Institute of Information and Communication Technology, Kwara State Polytechnic, Ilorin. \\ ${ }^{3}$ Department of Business and Entrepreneurship Education, Kwara State University, Malete P.M.B 1530, Ilorin \\ Kwara State, Nigeria
}

\begin{abstract}
The study was carried out to compare Computer Assisted Instruction and Traditional Methods of Teaching Keyboarding among Polytechnic Students in South West Geo-Political Zone, Nigeria. In order to achieve this, one specific objective was raised. In line with the specific objectives, four research questions and hypotheses were formulated for the study. Experimental design, specifically pretest-posttest control group design, was adopted for the study. The population for the study comprised of nine hundred and eighty students (980) from ten Polytechnics. Out of these, six Polytechnics used for the study were purposively selected from ten Polytechnics in South West Geo-Political zone, Nigeria. Thirty (30) students from each of the six (6) Polytechnics made up of the sample size of one hundred and eighty students (180) who were selected for the study through random sampling. The instrument used for data collection was Keyboarding Speed and Accuracy Test (KSAT), which was duly validated with a split-half reliability coefficient of 0.81 . The data collected were statistically analyzed using mean and standard deviation for the research question. The null hypothesis was tested using Analysis of Covariance (ANCOVA) at 0.05 level of significance. The findings include among others that, the computer-assisted instruction group was better in keyboarding speed and accuracy than the traditional method group because of the significant difference found between the speed and accuracy mean scores of students taught using computer-assisted instruction and those taught using traditional methods. The study concludes that computer-assisted instruction is a better method of teaching keyboarding. Based on the findings and conclusion, it was recommended among others that; Keyboarding teachers should use computer-assisted instruction method in teaching speed and accuracy in keyboarding and that Polytechnic Management should also provide necessary facilities such as computers and software that will facilitate effective teaching and learning of keyboarding skills using Computer Assisted Instruction.
\end{abstract}

Keywords: Computer, Assisted, Instruction, Traditional, Methods, Keyboarding

DOI: $10.7176 / \mathrm{JEP} / 12-10-09$

Publication date: April $30^{\text {th }} 2021$

\section{Introduction}

The introduction of computer-based courses to the curriculum of the secretarial profession in Polytechnics as reviewed by the National Board for Technical Education (NBTE) 2004 brought about fast understanding and qualities in learning of secretarial students. In this era of technology, the computer is a critical element in Information and Communication Technology. The computer has been referred to as a device that has turned the whole world into a global village. Information and Communication Technology (ICT) makes the transfer of information faster and easier. The computer has become a significant component of ICT, which has many advantages in this modern technological era.

World Economic Forum (2011) emphasized computer literacy with a statement that "the economic growth of a country depends on qualified labour and it is necessary that the university graduates are literate of technology for this labour to be used in 2020."

Computer literacy involves a set of abilities requiring individuals to communicate effectively with the computer system and as a basis for lifelong learning (Adeleke, .2003). It is common and relevant to all disciplines, learning environments and all levels of education. This view was upheld by Ige, (2005) who asserted that with the rate of growth of computer development, every aspect of man's life would be on the computer. He went further that, whoever neglects the study and use of computer today does so at his detriment. No wonder in the past, only people that can neither read nor write were illiterate, but in this era of technological advancement, whoever that cannot operate a computer would also be seen as an illiterate person. 
The computer appears to be the best audio-visual material that has ever been devised. It is such a comprehensive device that allows for the use of about $60 \%$ of the sense organs. These organs are those of sight, touch, and hearing. These are the organs that are useful for more effective learning. About $75 \%$ of learning occurs through seeing, $13 \%$ through hearing and $6 \%$ through feeling or touching. Only 3\% of learning takes place through smelling (Oyedele, 2005). The application of computer, especially in teaching and learning is limitless; that is, there is almost nothing about teaching and learning or instructional aids that cannot be computerised. Therefore, the use of Computer Assisted Instruction for the teaching and learning of Keyboarding in Polytechnics will bring about effectiveness in terms of speed, accuracy, prompt feedback, self-assessment, learning autonomy and enhance academic performance in teaching and learning of keyboarding as a subject by secretarial students.

Computer Assisted Instruction is an instructional technology which can be designed for a course and used for teaching and learning both within and outside the classroom setting. Computer Assisted Instruction, also known as CAI, is a teaching process in which a computer is used to enhance the education of an individual. Instructional or CAI software that teaches specific skills and knowledge often narrowed to a specific content area and grade range. Computer Assisted Instruction can be used to describe Internet-based instruction using WebPages, web bulletin boards, newsgroups, video, and real audio. It can also be the use of computer technology in teaching and learning. Computer Assisted Instruction will simplify the teaching and learning of keyboarding and enhance students' understanding. It will make students learn and acquire the basic techniques and skills of keyboarding in an interactive way. It will bring the teaching and learning of keyboarding to the level of the student understanding through technology. Students will be allowed to repeat a practice session and practice repeatedly for proper control of techniques or skills.

Computer programs are user-friendly and can represent an idea through alluring activity, sound, and exhibition. They allow students to work at their own pace and solve problems individually or collectively. Information processing systems provide prompt feedback, which makes students know whether their solution is right or wrong. If the solution is not right, the information processing system shows students how to resolve the problem correctly. Computer Assisted Instruction draws students' thinking ability in the light of the fact that they are user-friendly and make students participate actively in the learning process resulting in higher scores. It moves with the students' level of understanding and does not go ahead of the students until they have acquired expertise in the skill. Keyboarding is an art that enables an individual to acquire skills which involve pressing of the keyboard with the fingers through the mastery of the keys to produce varieties of documents on the typewriter or computer. Each hand made its assignment of fingers to keys. A touch typewriting method which is widely used today involves the use of all eight fingers to type without looking at the keys (Abraham-Ibe, \& Okonkwo, 2011). The main point behind keyboarding is techniques, and the hypothesis for this instructional method is in the domain of educators and the way by which the lesson is delivered. Keyboarding is a vital practical skill that all learners must acquire, the art of keyboarding involves preparing fingers to react effectively and rapidly to press the right key, and one must continue to practice this art until it becomes effective and a skill. The goal for new students is the development of the skill to use the appropriate techniques, pressing the right keys quickly and accurately.

In line with this, Polytechnics are one of the higher institutions in Nigeria which are saddled with the responsibilities of training both low and medium level human resources in varieties of occupation or profession. The products of these institutions are expected to have acquired the necessary skills and competencies that can make them fit properly into society or the world of work after graduation. Therefore, for Polytechnics to meet these responsibilities there must be a concerted effort to move from traditional methods of teaching to modern, motivating and exciting methods such as CAI especially in this era of technological advancement.

Office Technology and Management departments are the departments where keyboarding is being taught in Polytechnics. Using modern techniques to teach keyboarding will boost the interest of learners, increase their speed and accuracy, and drastically reduce failure rates and the number of dropouts.

In view of the above, the traditional methods of teaching and learning such as demonstration, lecture method and others are becoming inadequate as approaches towards functional education. The traditional method of teaching, as meant in this paper is the method of teaching that is being used in teaching a course. 'Traditional' means what has been on the ground, what they are used to. 'Their tradition'. In this paper, the course is keyboarding, which is a practical course, the students go to the laboratory where the teacher shows them how to use the keyboard. The teacher explains how to place fingers on the keyboard and gives them exercises from the textbook for them to work on. The adverse situations in which teaching and learning take place make the traditional methods ineffective. To make teaching and learning to be effective in this knowledge-based economy, part of the solution is to provide better technical support for the learning environment (Punie, Zinnbarer, \& Cabrera, 2006).

The use of Computer Assisted Instruction for effective classroom teaching and learning has for a long time been introduced in the developed countries to improve the efficiency and effectiveness of education at all levels. 
The role of Computer Assisted Instruction in teaching and learning of keyboarding is to teach keyboarding creatively and serve as a complement to the old or traditional method in Polytechnics. The traditional method along these lines could be viewed as up to this point existing strategy for guidance in the typical classroom setting. Among the traditional techniques for guidance in the teaching and learning of keyboarding is the lecture method. Lecture strategy enables much information to be passed to the student and favours treatment of large classes. Despite this preferred standpoint, the lecture method does not promote active learning and there is no cooperation and interaction between the teacher and pupils in the lecture process unless in situations where other teaching methods, such as questioning and problem-solving activities, are incorporated into the lecture (Kaur, 2011).

It has along these lines turned out to be clear that the lecture strategy which is as of now the common instructing approach in Nigerian polytechnics is improper and insufficient for accomplishing the goals of educating and learning of keyboarding. There is, hence, a critical need to look for progressively successful strategies which are appropriate and effective in advancing the extent of skill acquisition in keyboarding in Nigerian polytechnics. This, therefore, constitutes the background information in which the study was conducted on the comparative study of Computer Assisted Instruction and traditional methods of teaching keyboarding among polytechnic students in South-west Zone, Nigeria.

The Computer has become an integral part of the day to day life as well as an integral part of the education system. Having Computer Assisted Instruction as part of the method of teaching and learning of keyboarding in polytechnics can prove very helpful. Keyboarding is one of the core skill subjects in secretarial option which students must master very well. There is a significant relationship between background knowledge of keyboarding and computer application (Yenice, 2003). He further suggested that the students of any computer programme should be exposed to the manipulation of that typewriter (keyboard) before they start the practical aspect of the computer study. This exposure is nothing other than the conscious effort on teaching methods that will enable these students to grasps the proper keyboarding. However, the method by which keyboarding is taught in polytechnics makes students lose interest in the secretarial option in Nigeria polytechnics (Temidayo, 2009). As a result of this, the researchers are of the opinion that, in this era of technology development, secretarial education or profession in Nigeria cannot be relevant to the present societal needs without preparing future labour force with the appropriate method. This will assist the lower and medium human resources level graduates from polytechnics to acquire the necessary technical skills needed to function effectively in their work. Secretarial education training in Nigeria might not be concrete without viable grooming of new age learners to successfully utilize the new ICT in their area of study (Clever, 2009). Therefore, there should be more proactive, creativity and dynamism of methods in teaching and learning of keyboarding.

There are three approaches to teaching keyboarding in the conventional classroom; they include horizontal, vertical and skip-around (Temidayo, 2009). Using any of the three approaches, in a group situation does not seem to facilitate enough student or teacher interaction (individualized teaching). None of the approaches makes it possible for the teacher to monitor each student's position or posture in relation to the keyboard and how keystroke is made. It is also not possible for the teacher to analyze each student's error and proffer solution within the lecture period.

Consequently, there is a delay in feedback, which in turn builds-up to poor students' performance, especially in speed and accuracy tests. Moderators of keyboarding answer scripts have consistently commented negatively on the accuracy and speed acquisition by keyboarding students (Temidayo, 2009). It has been found out that about $80 \%$ of keyboarding students lose all the marks allocated to this task in any keyboarding question paper (Temidayo, 2009). It is pertinent to find the most effective way of teaching and learning keyboarding so that less time is spent on its learning. It is also necessary to produce fast and accurate students in keyboarding as modern organisations rely on accurate and timely information for their survival and development. All these are the confronting problems which the study has addressed using empirical evidence. It is expected that the findings of the study will make students to appreciate the importance of using CAI in teaching and learning of keyboarding and most importantly to imbibe, embrace the culture and acquaint them generally with the various uses or application of ICT skills even after graduation. It will also assist keyboarding teachers in Polytechnics to be up and doing. It will gear them up to acquire the necessary skills on how to use or incorporate CAI to complement the conventional methods of teaching the students.

\section{Statement of the Problem}

Based on the researchers' interaction with students of some polytechnics in the Southwest geo-political zone, Nigeria, The researchers observed that keyboarding skills are ill-acquired by the students which is a worrisome situation that calls for concern. The polytechnic students who are expected to acquire proper keyboarding skills for producing professional documents are found picking and pecking when typing. They cannot type without looking at the manuscript, and the speed of typing is deficient. Could this situation be attributed to the inefficiency of the traditional or old method of instruction, which is predominantly used in teaching keyboarding? 
When the researchers interacted with the students, they complained that this method of teaching keyboarding is boring and does not motivate them, thereby making keyboarding challenging to learn. The teachers of keyboarding complained that despite their efforts in making students to acquire keyboarding skills, there is still a mass failure of students in keyboarding. From the foregoing, it becomes evident that there is a dire need for other methods of teaching to address this problem. Methods of teaching that will make students take responsibility for their learning. This becomes the problem which this study addressed using empirical evidence of Computer Assisted Instruction and traditional methods of teaching keyboarding among Polytechnic students in the Southwest Geo-political Zone, Nigeria. This study is unique because to the best of the researchers' knowledge; no study has been conducted to compare the effects computer-assisted instruction and lecture method on speed and accuracy skills in keyboarding in the South-west, Nigeria. This becomes the gap in the literature which the study filled.

\section{Purpose of the study}

The general objective of the study is to compare the Computer Assisted Instruction and traditional methods of teaching keyboarding among Polytechnic students in the South-west Geo-political Zone, Nigeria. The specific objectives are to:

1. compare the speed and accuracy of students being taught with Computer Assisted Instruction and traditional methods of teaching keyboarding in polytechnics in the South-west geo-political zone, Nigeria.

\section{Research Questions}

In line with each specific objective, the following research questions are formulated for the study within the scope of the South-west geo-political zone, Nigeria:

1. To what extent do the pretest and posttest speed and accuracy mean scores of students taught keyboarding with Computer Assisted Instruction method differ with the pretest and posttest speed, and accuracy mean scores of students taught keyboarding with the traditional method in polytechnics?

\section{Research Hypothesis}

In line with the research questions and within the scope of the South-west geo-political zone, Nigeria, the researcher tested the following null hypotheses:

H01: There is no significant difference between the mean score of speed and accuracy of students being taught with Computer Assisted Instruction and traditional methods of teaching keyboarding in polytechnics.

\section{Methodology}

The quasi-experimental research design was used to carry out the study; the schools were assigned to experimental and control groups. The population of the study comprised ND I students from 10 polytechnics who were admitted in 2017/2018 academic session in both state and Federal polytechnics in the South-west zone, Nigeria. There are a total number of 980 ND I students. The purposeful sampling technique was used to select six from the 10 polytechnics in the Southwest geo-political zone, Nigeria. Purposeful sampling was used because of the available facilities in each of this polytechnic. Thirty students were selected from each polytechnic. Three polytechnics were used each for experimental and control groups. The polytechnics selected were: Lagos State Polytechnic Ikorodu, Osun State Polytechnic, Ire, Rufus Giwa Polytechnic, Owo, The Polytechnic Ibadan, Federal Polytechnic, Ilaro, and Federal Polytechnic, Ado-Ekiti. Lagos State Polytechnic Ikorodu, was used as Computer Assisted Instruction group, Osun State Polytechnic, Ire as traditional method group, Rufus Giwa Polytechnic, Owo as Computer Assisted Instruction group, The Polytechnic Ibadan, as traditional method group, Federal Polytechnic, Ilaro as traditional method group, and Federal Polytechnic, Ado-Ekiti as Computer Assisted Instruction group. From the six polytechnics, the total number of 180 students were selected. This number comprised 90 males and 90 females randomly selected and randomly assigned to both Computer Assisted Instruction group and traditional method groups; that is, 30 students from each polytechnic. Keyboarding Speed and Accuracy Test (KSAT) was the instrument used for data collection. KSAT was duly validated with a splithalf reliability coefficient of 0.81 . The students were pretested, after which the treatment began. The treatment period lasted for four weeks. The experimental group was taught with the CAI method using Mavis Beacon Package while the control group was taught with the traditional method where the participants also had access to the computer but not with any software package. The two groups of participants had access to computers, but the only difference between them was that the experimental group which is CAI group were given computer and Mavis Beacon typing software to follow with very little facilitation from the teacher. The control group, on the other hand, were also given the computer, but without Mavis Beacon typing software rather the group was taught typing skills by the teacher. Mean, and standard deviation were used to answer the data for the research question, while Analysis of Covariance (ANCOVA) was used to test the hypothesis at the 0.05 level of significance. 


\section{Results}

Research Question 1

To what extent do the pretest and posttest speed and accuracy mean scores of students taught keyboarding with Computer Assisted Instruction method differ in polytechnics?

Table 1:Mean of pre-test and post-test scores of the treatment group taught keyboarding using Computer Assisted Instruction method

\begin{tabular}{|l|c|c|c|c|c|c|}
\hline GROUP & \multicolumn{2}{|c|}{ Experimental Group (CAI Method) } & \multicolumn{2}{c|}{ Control Group (Traditional Method) } \\
\hline & $\mathbf{N}$ & $\bar{X}$ & SD & N & $\bar{X}$ & SD \\
\hline PRE-TEST & 30 & 42.02 & 9.48 & 30 & 44.39 & 7.64 \\
\hline POST-TEST & 30 & 76.03 & 10.11 & 30 & 52.56 & 8.55 \\
\hline $\begin{array}{l}\text { MEAN \& SD } \\
\text { DIFFERENCE }\end{array}$ & & 34.01 & 0.63 & & 8.17 & 0.91 \\
\hline
\end{tabular}

Source: Field experiment, 2018

The data presented in Table 1 revealed that the treatment group taught keyboarding with Computer Assisted Instruction method had a mean score of 42.02 in the pretest and a mean score of 76.03 in the post-test with standard deviation of 9.48 and 10.11 for the pre-test and post-test, respectively, pre-test $(\bar{X}=42.02 ; \mathrm{SD}=9.48)$, post-test $(\bar{X}=76.03 ; \mathrm{SD}=10.11)$. The result gave a pre-test, post-test mean gain of the treatment group taught with Computer Assisted Instruction method to be 34.01. The low standard deviation difference (0.63) showed that the scores of students in both the pre-test and post-test are clustered around their respective mean scores. The traditional method had a mean score of 44.39 and standard deviation of $7.64(\bar{X}=44.39$; SD $=7.64)$ in the pretest and mean score of 52.56 and standard deviation of $8.55(\bar{X}=52.56$; $\mathrm{SD}=8.55)$ in the posttest, giving a pre-test post-test mean gain in the control group taught keyboarding with a traditional method to be 8.17. With this result, Computer Assisted Instruction method is effective in improving students' speed and accuracy in keyboarding. The CAI group did better by far than the traditional method group.

\section{Test of Hypothesis}

The null hypothesis for the study was tested using Analysis of Covariance (ANCOVA) at 0.05 level of significance, and the summaries are presented in Tables 7 to 9 as follows:

$\mathrm{H}_{01}$ : There is no significant difference between the mean score of speed and accuracy of students being taught with Computer Assisted Instruction and traditional methods of teaching keyboarding in polytechnics.

Table 2: Summary of Analysis of Covariance (ANCOVA) for Test of Significance of difference between the mean score of speed and accuracy of students being taught with Computer Assisted Instruction and traditional methods of teaching keyboarding

\begin{tabular}{|l|l|l|l|l|l|}
\hline Source & Type III Sum of Squares & Df & Mean Square & F & Sig. \\
\hline Corrected Model & $1231.051^{\mathrm{a}}$ & 4 & 307.014 & 3.119 & .002 \\
\hline Intercept & 7688.775 & 1 & 7688.775 & 102.838 & .000 \\
\hline Pretest & 474.145 & 1 & 474.145 & 5.486 & .021 \\
\hline Treatment & 947.330 & 1 & 947.330 & 12.862 & .000 \\
\hline Gender & 164.322 & 1 & 163.322 & 1.880 & .124 \\
\hline Treatment*gender & 5.360 & 1 & 6.360 & .064 & .674 \\
\hline Error & 4543.507 & 88 & 86.435 & & \\
\hline Total & 214522.000 & 90 & & & \\
\hline Corrected Total & 10067.562 & 89 & & & \\
\hline a. R Squared =.141 (Adjusted R Squared $=.107)$ & & & \\
\hline
\end{tabular}

Source: Field experiment, 2018

The data presented in Table 2 showed F-calculated values for the effects of treatment of Computer Assisted Instruction method on students' speed and accuracy in keyboarding. The Table showed that there was a significant main effect of treatment of Computer Assisted Instruction on speed and accuracy of polytechnics students in keyboarding $(\mathrm{F}=12.862 ; \mathrm{P}=000)$. Hence, the null hypothesis that stated that there is no significant difference between the mean score of speed and accuracy of students being taught with Computer Assisted Instruction and traditional methods of teaching keyboarding was therefore rejected. This implied that teaching 
with Computer Assisted Instruction method has a positive effect on the speed and accuracy of polytechnic students in keyboarding. This means that the effect observed is due to the main treatment given to students.

Table 3: Estimated marginal means of both the treatment and control groups

\begin{tabular}{|l|c|c|}
\hline Groups & Mean & Std. Error \\
\hline Treatment & 67.27 & 1.161 \\
\hline Control & 49.98 & 1.503 \\
\hline
\end{tabular}

\section{Source: Field experiment, 2018}

The data in Table 3 showed estimated marginal means for the two groups, i.e. the adjusted mean after the covariance. The Table revealed that the participants in the experimental group performed better than their counterparts in the control group because they had the highest adjusted post mean score (mean $=67.27$ ) as against the adjusted posttest mean score of the control group (mean $=49.98$ ). The implication here is that teaching with Computer Assisted Instruction method is effective for improving the speed and accuracy of polytechnics students in keyboarding far more than the traditional method.

\section{Discussion}

The study found that there was a significant difference between the speed and accuracy of students taught using computer-assisted instruction and traditional method $(\mathrm{F}=12.862 ; \mathrm{P}=000)$. This could also be seen from the mean performance of Computer Assisted Instruction of 76.03, which was greater than the mean of 44.39 for students taught using the traditional method. The students taught with computer-assisted instruction method performed better in terms of speed and accuracy than those taught with the traditional method. The mean difference showed that the computer-assisted instruction group was better than the traditional method group by 34.01 mean differences. This implied that the computer-assisted instruction method is more effective in teaching speed and accuracy in keyboarding than the traditional method. This finding supports the earlier finding of (Achilike, 2002) who found that computer-assisted instruction method of teaching keyboarding speed and accuracy led to the greater acquisition of speed and accuracy in keyboarding by the students. Speed and accuracy skill can be acquired when students learn to keyboard without looking at the keys. This is also in line with [9] who found 58.6\% failure in control groups post-test where the computer Assisted Instruction method of teaching keyboarding skills was not used. That was why (Oyeyiola, 2006) pointed out that computer-assisted instruction method of keyboarding promotes faster speed and accuracy, acquisition of proper skills and techniques of keyboarding. This, therefore, makes it clear that if students are taught keyboarding with CAI, their academic performance will be better and proper skills will be acquired.

\section{Conclusion}

Based on the finding of the study which revealed that CAI students performed better in speed and accuracy than the traditional method students, it was therefore concluded that Computer Assisted Instruction method is better than the traditional method of teaching keyboarding. The implication here is that the Computer Assisted Instruction method of teaching keyboarding speed/accuracy is a more effective teaching method for acquiring keyboarding skills and techniques. Since this is the case, it means that the continuous use of the traditional method in teaching keyboarding will continue to negatively affect students' acquisition of proper keyboarding skills which will adversely affect their performance in the modern office when they eventually graduate.

\section{Recommendations}

1. Keyboarding teachers should use computer-assisted instruction method in teaching speed and accuracy in keyboarding.

2. There is the need for the State and Federal Governments to encourage keyboarding teachers to go for in-service training or refresher courses to acquire additional qualifications in keyboarding skills to be able to incorporate gender equality in the teaching of keyboarding.

3. Polytechnic Management should also provide necessary facilities like computers and software that will help the effective acquisition of keyboarding skills using Computer Assisted Instruction.

4. National Board for Technical Education (NBTE) should recommend the application of Computer Assisted Instruction in teaching and learning keyboarding skills and competencies in various Polytechnics in Nigeria.

\section{References}

Abraham-Ibe, I. G. \& Okonkwo, D. A. (2011). Enhancing Entrepreneurship in Business Education through Communication with Keyboarding. Book of Reading, Association of Business Educators of Nigeria. 1(11) 11-16.

Achilike, A. N. (2002). Extensive Teaching Versus Extensive Supervision in the Teaching of Keyboarding: 
Secondary Students' Choice of Style”. Business Education Journal. 3(5) 202.

Adeleke, I. A. (2003). Computer Literacy for all Students in the College of Education: Problems and Prospects. Nigeria Educational Review, 8(1) 24-29.

Clever, O.I. (2009). Issues of ICT Assessment in Teaching and Learning of Business Education courses. Business Education Journal. 7(1), 34-41

Ige, N. (2002). Information Technology, and Nigeria Education. Journal of Education Research and Development, 4(1), 16-24.

Kaur. G. (2011). Study and Analysis of Lecture Model of Teaching. International Journal of Educational Planning \& Administration 1(1), 9-13. Retrieved from http://www.ripublication.com/ijepa.htm on 12/4/2019.

National Board for Technical Education (NBTE) (2004). Office Technology and Management Curriculum and Course Specifications, Kaduna.

Oyedele, J.F. (2005). Technology utilisation in Business Education: Business Education Journal, Nigerian Association of Business Educators. 3(5) 181- 193.

Oyeyiola, A. O. (2006). Professional and Personal Computer Users' Perception of Keyboarding Skills and its Implication on Business Education Curriculum". Kaura Namoda Journal of General Education. 7(2).19-23.

Punie, Y., Zinnbarer, D., \& Cabrera, M. (2006). .A Review of the Impact of ICT on Learning. European Commission Joint Research Centre.

Temidayo, A.O. (2009). Effect of Non-Programmed and Programmed Instructions on the performance of students in Typewriting. Secretarial Forum, Journal of Department of Office Technology and Management, School of Business Studies. The Federal Polytechnic Ede, Osun State.4(1), 7-11.

World Economic Forum, (2011). Global talent risk - Seven responses. Geneva. Assessed in Assessing the computer literacy of university graduates. Available from: https://www.researchgate.net/publication/308349331_Assessing_the_computer_literacy_of_university graduates [accessed Mar 17 2019].

Yenice, N. (2003). The Effect of Computer Assisted Science Teaching on Students' Science and Computer Attitudes. The Turkish Online Journal of Educational Technology, 2(4), 12. 